\title{
Surgical Angioplasty for Left Main Coronary Artery Disease - A Case Report
}

\author{
PK Chanda, H Rasheed, M Sharifuzzaman, MH Rahaman, MA Hossain, S Dasgupta, F Ahmed \\ National Heart Foundation Hospital \& Research Institute, Dhaka.
}

Keywords: LMCA, PCI, Surgical angioplasty.

\begin{abstract}
:
Conventional treatment of left main coronary artery (LMCA) disease includes coronary artery bypass graft $(C A B G)$ and more recently, in selective indications, percutaneous coronary intervention (PCI). Direct surgical patch angioplasty of the LMCA using fresh autologous pericardium, saphenous vein, or mammary artery patch can be proposed as an alternative treatment. We have successfully operated one patient with surgical angioplasty for isolated ostial left main coronary stenosis at National Heart Journal.
\end{abstract}

(Cardiovasc. j. 2010; 3(1): 110-112)

\section{Introduction:}

Isolated ostial left main coronary artery stenosis is an unusual cause of angina. The ostium may be narrowed due to atherosclerosis, fibromuscular dysplasia, and more rarely by syphilis or Takayasu's arteritis. Isolated ostial left main coronary stenosis is a distinct clinical entity primarily affecting middle-aged women ${ }^{1}$. The traditional surgical treatment is coronary artery bypass grafting. Direct surgical approach to LMCA stenosis is not a new idea. The first cases of LMCA reconstruction were described by Effler ${ }^{2}$ and Sabiston ${ }^{3}$ in 1965. In 1983, Hitchcock ${ }^{4}$ and colleagues successfully revived the concept of a transaortic approach to the LMCA, which encouraged a few surgeons like Sullivan ${ }^{5}$, Deuvaert ${ }^{6}$ and Dion $^{7}$ to perform a surgical angioplasty of the LMCA in selected patients.

Various techniques reported for exposing the left main coronary artery include posterior, anterior, and transpulmonary ${ }^{4-8}$. We have successfully used transpulmonary approach in one (01) patient for isolated ostial left main coronary artery stenosis.

\section{Case Report:}

A 50 years old female hypertensive, nondiabetic asthmatic house wife got admitted in NHFH \& RI on $30^{\text {th }}$ March 2010 with a diagnosed case of CAD for CABG operation. Her CAG revealed LM disease with 80\% ostial stenosis (Fig.-1).Her LAD, LCx and RCA are free from any disease with LVEF-60\%. On 08.04.2010 she was prepared for surgical angioplasty.

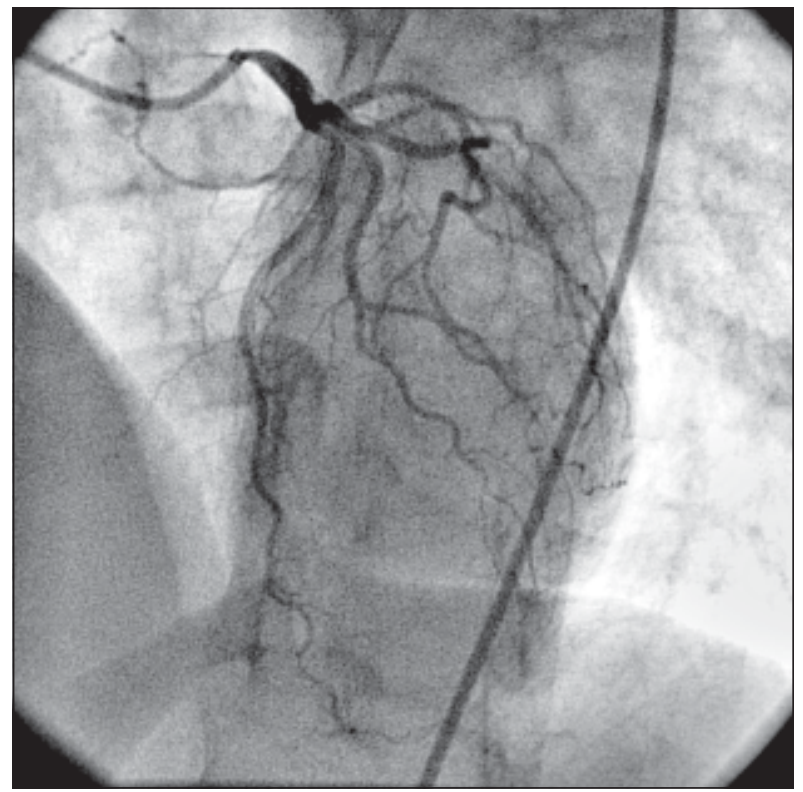

Fig.-1: Preoperative angio shows critical LMostial lesion.

The chest was opened through a midline sternotomy. A small triangular patch of autologous pericardium was harvested and kept aside in saline. After heparinization, cardiopulmonary bypass was established by cannulating the ascending aorta and using a standard two-stage venous cannula. The 
patient was kept normothermic. The aortopulmonary window was dissected and the aorta was mobilized. Cardioplegia was administered through the aortic root after cross clamping the aorta. A left ventricular vent passed through the right superior pulmonary vein helps keep the operative field clear. The pulmonary artery was transected approximately $1 \mathrm{~cm}$ below the bifurcation. The pulmonary artery was spread open on silk stay sutures. The aorta was nicked transversely and then split longitudinally posteriorly down into the orifice of the left main coronary artery. The left main coronary artery was opened posteriorly for approximately $1 \mathrm{~cm}$. The autologous pericardium was shaped into a wedge measuring approximately $2 \mathrm{~cm}$ wide at the top and narrowed down to a point. The apex of the pericardial patch was then sutured to the apex of the slit into the posterior left main coronary artery. A running 7-0 polypropylene suture was used on either side. Finally, the ascending aorta and pulmonary artery were put back together using a running 4-0 polypropylene suture in a double layer. Posteriorly the proximal aorta is $1.5 \mathrm{~cm}$ wider after sewing the patch in place (Fig 2). The air was removed from the heart and the aorta and the

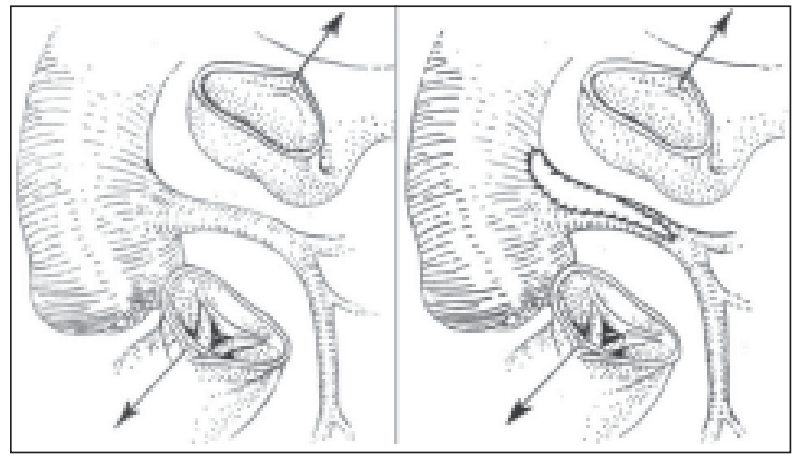

Fig.-2: Transpulmonary anterior approach and surgical patch plasty of the left main coronary artery

cross clamp was released. After ensuring hemostasis of the suture line, the patient was weaned off cardiopulmonary bypass and shifted to ICU.

She was extubeted on the next morning and discharged home on $8^{\text {th }}$ POD. Before discharge check CT Angio was done showing good calibred LM with no distal obstruction (Fig 3).

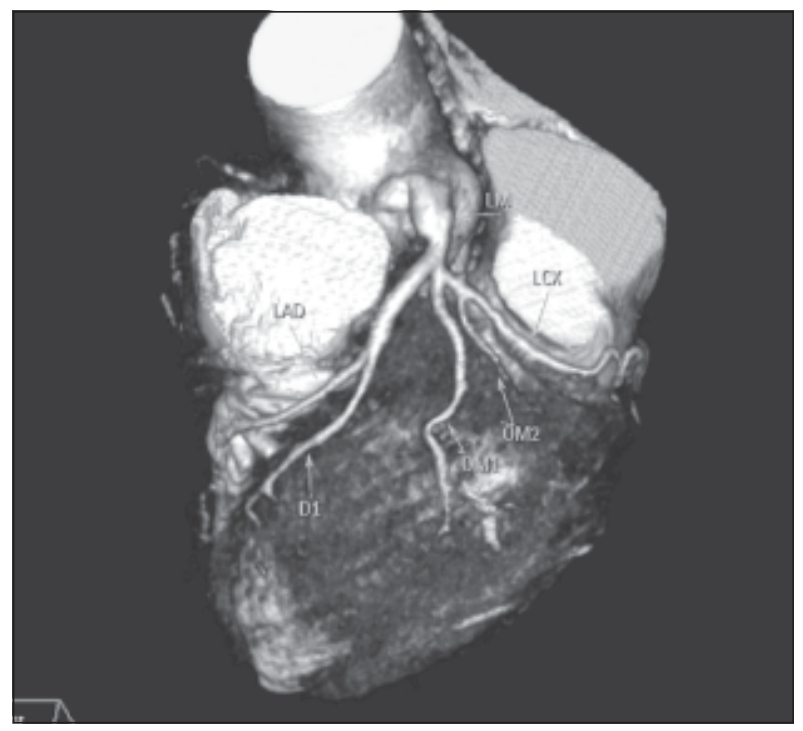

Fig.-3: Postoperative check CT angio shows good caliber LM with no distal obstruction

\section{Discussion:}

Coronary artery bypass grafting is the conventional and safe method of treating stenosis of the left main ostium. However, it has potential pitfalls, such as the need to harvest conduits, progressive occlusion of the left main coronary artery leading to graft dependent coronary circulation and atherosclerotic changes of venous grafts if used. Direct surgical angioplasty restores native antegrade flow. It also maintains intraluminal access to the distal coronary tree for future PCI. Arterial and venous conduits are preserved for possible use in the future. ${ }^{1}$

There have been several methods described for approaching the left main coronary artery. In the anterior approach, the incision starts at the front of the ascending aorta and extends leftward toward the left main ostium. ${ }^{7}$ The incision cross the left main ostium is made anteriorly. This approach gives good exposure, but the patch is sutured at the acute angle formed by the aortic wall with the left main ostium. This poses the risk of future stenosis. The posterior approach described by Hitchcock and coworkers ${ }^{4}$ uses a spiral aortotomy. The aorta is opened from left to right, and the incision extends across the top of the commissure between the noncoronary cusp and the left coronary cusp. The posterior wall of the left main coronary artery is incised across the stenosis. This approach is straightforward, avoids the acute angle, 
but exposure is poor. The third approach described by Villemot and colleagues 8 is the transpulmonary approach. Visualization of the left main coronary artery is achieved better by transecting the main pulmonary artery.

\section{Conclusion:}

Surgical angioplasty of the coronary ostia restores physiologic perfusion of the myocardium, maintains intraluminal access to the distal coronary tree, and saves bypass material.

In conclusion, like an increasing number of surgeons we believe that LMCA surgical angioplasty is safe and reproducible, provided that well-defined contraindications are respected: there should be no involvement of the distal bifurcation and no heavy calcifications on the preoperative angiogram.

\section{References:}

1. Jayesh Dhareshwar, Kenton J. Zehr, and Hartzell V. Schaff. Surgical Ostioplasty for Isolated Left Main Stenosis: Ann Thorac Surg 2007;83:1562-3.
2. Effler DB, Sones FM, Favaloro R, Groves LK. Coronary endarterectomy with patch graft reconstruction: clinical experience with 34 cases. Ann Surg 1965; 162:590-601.

3. Sabiston DC, Ebert PA, Friesinger GC, et al. Proximal endarterectomy: arterial reconstruction for coronary occlusion at aortic origin. Arch Surg 1965; 91:758-64.

4. Hitchcock JF, Robles de Medina EO, Jambroes G. Angioplasty of the left main coronary artery for isolated left main coronary artery disease. J Thorac Cardiovasc Surg 1983; 85:880-884.

5. Sullivan JA, Murphy DA. Surgical repair of stenotic ostial lesions of the left main coronary artery. $J$ Thorac Cardiovasc Surg 1989;98:33-36

6. Deuvaert FE, De Paepe J, Van Nooten G, Peperstraete B, Primo G. Transaortic saphenous patch angioplasty for left main coronary artery stenosis. J Cardiovasc Surg 1988;29:610-613.

7. Dion R, Elias B, El Khoury G, et al. Surgical angioplasty of the left main coronary artery. Eur $J$ Cardiothorac Surg 1997;11: 857-64.

8. Villemot JP, Godenir JP, Peiffert B, et al. Endarterectomy of the left main coronary artery stenosis by a "transpulmonary artery approach." Eur $J$ Cardiothorac Surg 1988; 2:453-7. 